and ethnology); arts and letters; institutions and social processes (political, economic, juridical, human geography); natural sciences and technology. Over the eight working days of the Congress each of the sections held five meetings, one of which was a general session at which one or more speakers reviewed work in the relevant field. Public lectures were also given by Professor Daryll Forde on 'The Development of African Studies' and by Professor Roger Bastide on 'Contrasts in African and European Thought'. The text of a public lecture by Dr. Robert Gardiner, Secretary-General of the Economic Commission for Africa (who was unable to attend), was distributed during the Congress.

The Congress was opened by President Léopold Sédar Senghor with an address on the needs and opportunities for African cultural studies. During the closing session M. Amadou Seydou, the Director of the Department of Culture of Unesco, reviewed the opportunities for contributions by the Congress to the work of Unesco.

An Editorial Committee, of which the Secretary-General of the Congress, Professeur Alassane N'Daw of the University of Dakar, will act as rapporteur, will prepare for publication a report of the work of the Congress, including the main addresses, a selection of the papers presented at the Congress, and the recommendations adopted by the Permanent Council and the closing plenary session.

Some revisions of the statutes of the Congress were adopted, mainly to bring the English and French texts into strict accordance and also to provide for its continuing organization. The revised statutes and the definitive texts of the recommendations are being prepared for early distribution.

A recommendation that the next Congress to be held within five years should be held in eastern Africa was adopted by the Permanent Council which has also invited Professor Aklilu Habte (of the Haile Sellassie I University of Addis Ababa) to accept the Presidency and Dr. N. Otieno (of University College, Nairobi) to serve as Secretary-General for the next Congress. Requests for further information concerning the work of the Congress should be addressed to: Professeur Alassane N'Daw, Faculté des Lettres, Université de Dakar, Fann, Dakar, Senegal.

\title{
The Use of Oral Data for African Studies
}

A CONFERENCE on the use of oral data for African studies, attended by some twenty scholars from American universities, was held at the University of Wisconsin ih Madison on I and 2 June 1967, under the sponsorship of the Oral Data Committee of the African Studies Association. The original aim was to assign a series of draft chapters for a manual dealing with the problems of using oral data for research in the various disciplines. After the conference, however, it appeared that while some disciplines were already well provided for, others had almost nothing on appropriate field techniques for collecting oral data. The committee has therefore decided to publish the proceedings of the conference, but not a manual. The need for a manual on field techniques in the discipline of history was to be met by separate publication of the paper on that subject in the Journal of African History. Professor Jack Berry, Northwestern University, is to act as general editor of the conference proceedings. The committee agreed to dedicate the publication to the late Hans Wolff, who made his final scholarly appearance at the conference.

\section{Second Conference on Oral History in Tanzania}

THE second conference of historians currently working from oral sources in Tanzania was held at the University College, Dat es Salaam, on 6 and 7 January 1968. The discussions were mainly concerned with field-work methods and problems of interpretation, since papers on recent research into pre-colonial history had already been presented to the 